\title{
Long-term outcomes of a randomized controlled trial on brief alcohol interventions for job-seekers
}

\author{
Inga Schnuerer ${ }^{1 *}$, Sophie Baumann ${ }^{1}$, Beate Gaertner ${ }^{2,3}$, Katja Haberecht $^{1}$, Gallus Bischof ${ }^{4}$, Ulrich John ${ }^{1}$, \\ Jennis Freyer-Adam \\ From International Network on Brief Interventions for Alcohol and Other Drugs (INEBRIA) Meeting 2013 \\ Rome, Italy. 18-20 September 2013
}

In the past three decades, two paths of how to understand and support health behavior change have been followed: stage-tailored models and continuum models. Our aim was to investigate the comparative efficacy of a stagetailored intervention and a non-stage-tailored intervention of the same intensity in reducing alcohol use and alcohol problem severity among job-seekers with unhealthy alcohol use. The interventions were based on the most prominent representative models, the transtheoretical model of behavior change (TTM) and the theory of planned behavior (TPB). A total of 1,243 proactively recruited job-seekers with unhealthy alcohol use (64\% male, $\mathrm{M}=30$ years, $76 \%$ not motivated to change) were assigned by random to three study groups: (1) individualized stage-tailored feedback letters based on the TTM, (2) individualized nonstage-tailored feedback letters based on the TPB, and (3) assessment only (controls). Both intervention groups received up to two interventions. All groups were followed-up three, six and 15 months after baseline. Piecewise latent growth models were conducted to investigate change in alcohol use and severity from baseline to month 3 and month 3 to 15 . Initial motivation was tested as a moderator of intervention efficacy. All groups reduced alcohol use and severity significantly in the short term. In the long term and when including motivation as a covariate, the stage-tailored group produced a significantly greater reduction than the two other groups. Initial motivation was a significant moderator of intervention efficacy. Neither intervention was generally more or less effective than the other. The efficacy of the interventions largely depended upon the initial motivation to change alcohol use: the lower the motivation to change, the more likely

\footnotetext{
* Correspondence: inga.schnuerer@uni-greifswald.de

'Institute of Epidemiology and Social Medicine, University Medicine Greifswald, Greifswald, Germany

Full list of author information is available at the end of the article
}

the individuals were to benefit from the stage-tailored intervention; and the higher the motivation to change, the more likely the individuals were to benefit from the nonstage-tailored intervention.

\section{Authors' details}

'Institute of Epidemiology and Social Medicine, University Medicine Greifswald, Greifswald, Germany. ${ }^{2}$ Institute of Biometry and Clinical Epidemiology, Charité University Medicine Berlin, Berlin, Germany. ${ }^{3}$ Department of Epidemiology and Health Monitoring, Robert Koch Institute, Berlin, Germany. ${ }^{4}$ Department of Psychiatry and Psychotherapy, Medical University of Lübeck, Lübeck, Germany.

Published: 4 September 2013

doi:10.1186/1940-0640-8-S1-A69

Cite this article as: Schnuerer et al: Long-term outcomes of a randomized controlled trial on brief alcohol interventions for jobseekers. Addiction Science \& Clinical Practice 2013 8(Suppl 1):A69.

Submit your next manuscript to BioMed Central and take full advantage of:

- Convenient online submission

- Thorough peer review

- No space constraints or color figure charges

- Immediate publication on acceptance

- Inclusion in PubMed, CAS, Scopus and Google Scholar

- Research which is freely available for redistribution

Submit your manuscript at www.biomedcentral.com/submit

\section{() Biomed Central}

C Biomed Central

C 2013 Schnuerer et al; licensee BioMed Central Ltd. This is an Open Access article distributed under the terms of the Creative Commons Attribution License (http://creativecommons.org/licenses/by/2.0), which permits unrestricted use, distribution, and reproduction in any medium, provided the original work is properly cited. 